\title{
Causal influences in haematemesis and melaena
}

\author{
G. H. JENNINGS \\ From Edgware General Hospital, Middlesex
}

EDITORIAL SYNOPSIS 'The gun must be loaded in order for an explosion to occur when salicylates pull the trigger' (Grossman, Matsumoto, and Lichter, 1961). This study substantiates this aphorism. The series of cases particularly emphasizes the importance of extrinsic factors, such as excessive emotion, fatigue, anxiety, infection, alcohol, irregular meals, and heavy smoking, which may contribute singly or jointly to a bleeding episode.

The official figures have in recent years shown an increasing incidence of peptic ulcer, and particularly of chronic duodenal ulcer, in both sexes (Avery Jones, 1957). It does not seem likely that this large increase can be ascribed to intrinsic constitutional factors (familial tendency, age, sex, blood group) and to discover its cause external circumstances need to be considered.

One of the striking ways in which the increased incidence of ulcer is seen in the wards of a general hospital is in the large number of cases of haematemesis and melaena admitted, and it was felt that by careful consideration of such cases of bleeding ulcer some clues might be obtained as to the causes of the total increase in incidence and in particular as to the nature of any deleterious external influences.

\section{MATERIAL}

The patients were those admitted to the general wards of the hospital and were consecutive during four years (1958-61 inclusive). The wards to which they were admitted were equal-sized male and female units with a total of 70 beds under the care of the writer and all the patients were questioned and examined by him soon after admission.

The area from which they came is one of the very large suburban areas characteristic of modern city development and its population is a mixed one with a predominance of business men and tradespeople, many of the former commuting daily to London; there is also a fair sprinkling of professional men. The area is generally prosperous, with a moderate number of factories and light engineering premises. Two or three of the districts are of lesser affluence but there was little unemployment in the area during the time of the survey.

In this period 321 cases were considered with 338 admissions for haemorrhage, 16 patients being admitted twice and one three times. The types of case are shown in Table $I$ in which the age and sex distribution can also be seen. A total of 244 men and 93 women were admitted, 227 men and 87 women being ulcer cases. Of the 314 admissions for ulcer in the series, 172 were classified as acute and 142 as chronic. The diagnosis was made as between acute and chronic ulcers on historical and radiological evidence, and while this is not completely accurate it was felt to be reasonably reliable. Most of the patients were in hospital for about four to five weeks from the onset of the haemorrhage and they were radiographed at the end of this period. Those who had no ulcer crater visible on the radiograph, or who merely showed mucosal changes or duodenal irritability, were classified as acute. At first those with duodenal irritability, of which there were 28, were classified as acute duodenal ulcers, but this was later considered an uncertain division and has been excluded from the account. Historical evidence, in general, supported the radiological findings, being of none or brief and uncharacteristic previous dyspepsia in the radiologically negative cases. The incidence of chronic ulcer showed the characteristic male predominance, only 20 of the 142 patients admitted being women.

\section{NATURE OF PROVOCATIVE FACTORS}

ASPIRIN In seeking the causes of the ulceration and its exacerbation which had led to haemorrhage, a strikingly large proportion of acute ulcers was first noted, and, as it is known that aspirin will lead to an acute haemorrhagic erosive gastritis (Muir and Cossar, 1955) in a number of those who take it, careful note was made of the patients' history of aspirin taking both past and recent and also of the type of preparation used. It was found that 205 of the ulcer cases $(65 \%)$ had taken aspirin within 48 
TABLE I

TYPE AND AGE DISTRIBUTION OF BLEEDING ULCERS

\begin{tabular}{|c|c|c|c|c|c|c|c|c|c|c|c|c|c|}
\hline & \multirow{3}{*}{$\begin{array}{l}\text { Age } \\
(y r .)\end{array}$} & \multicolumn{4}{|c|}{ Acute Ulcer } & \multicolumn{4}{|c|}{ Chronic Duodenal Ulcer } & \multicolumn{4}{|c|}{ Chronic Gastric Ulcer } \\
\hline & & \multicolumn{2}{|c|}{ No Operation } & \multicolumn{2}{|c|}{ Operation } & \multicolumn{2}{|c|}{ No Operation } & \multicolumn{2}{|c|}{ Operation } & \multicolumn{2}{|c|}{ No Operation } & \multicolumn{2}{|c|}{ Operation } \\
\hline & & $M$ & $F$ & $M$ & $F$ & $M$ & $F$ & $M$ & $F$ & $M$ & $F$ & $M$ & $F$ \\
\hline \multirow[t]{8}{*}{ Aspirin group } & -20 & 2 & 2 & - & - & - & - & - & - & - & - & - & - \\
\hline & $21-30$ & 2 & 2 & - & - & 5 & 1 & - & - & - & - & - & - \\
\hline & $31-40$ & 13 & 1 & 1 & - & 4 & 3 & 2 & - & - & - & - & - \\
\hline & $41-50$ & 12 & 7 & $3^{1}$ & 1 & 3 & 1 & 3 & - & 2 & 1 & - & - \\
\hline & $51-60$ & 20 & 9 & 2 & - & 16 & 2 & 3 & - & 3 & - & - & - \\
\hline & $61-70$ & 10 & 10 & - & - & 12 & - & 4 & - & 3 & 2 & 2 & - \\
\hline & $71-80$ & 7 & 12 & - & - & 5 & - & - & - & 1 & 2 & 1 & 1 \\
\hline & $81-90$ & 2 & 4 & - & - & - & - & - & - & - & 1 & - & - \\
\hline Totals & & 68 & 47 & 6 & 1 & 45 & 7 & 12 & - & 9 & 6 & 3 & 1 \\
\hline \multirow[t]{8}{*}{ Non-aspirin group } & -20 & - & - & - & - & - & - & - & - & - & - & - & - \\
\hline & $21-30$ & 4 & 2 & - & - & 3 & - & - & - & - & - & - & - \\
\hline & $31-40$ & 2 & 2 & - & - & 4 & - & 1 & - & - & - & - & - \\
\hline & $41-50$ & 7 & 1 & - & - & 8 & 2 & 2 & 1 & 1 & - & 1 & - \\
\hline & $51-60$ & 8 & 3 & - & - & 7 & 1 & - & - & 4 & - & $1^{1}$ & - \\
\hline & $61-70$ & 6 & 6 & - & - & 10 & $i$ & - & - & 4 & - & 1 & - \\
\hline & $71-80$ & 4 & 4 & - & - & 4 & $i$ & - & - & - & - & 1 & - \\
\hline & $81-90$ & - & $i$ & - & - & - & - & 1 & - & - & - & - & - \\
\hline Totals & & 31 & 19 & - & - & 36 & 5 & 4 & 1 & 9 & - & 4 & - \\
\hline Grand totals & & 99 & 66 & 6 & 1 & 81 & 12 & 16 & 1 & 18 & 6 & 7 & 1 \\
\hline
\end{tabular}

${ }^{1}$ One also had chronic duodenal ulcer.

hours of the onset of haemorrhage while 109 had not. Of the 205 aspirin cases, 122 were classified as of acute and 83 as of chronic ulcers. It is, of course, evident that if aspirin causes an acute erosive gastritis it is unlikely that even the 83 cases were all or even largely bleeding from the chronic ulcer shown in the final radiograph and suggested by the previous history. It is known that chronic duodenal ulcers in particular react with an extreme erosive gastritis to aspirin (Muir and Cossar, 1955) while chronic gastric ulcers may be naturally associated with erosive gastritis. My colleague, Mr. Frank Forty (personal communication), very frequently finds haemorrhagic erosive gastritis as the cause of bleeding even where a chronic ulcer is present. This fact has to be remembered when planning the treatment of a bleeding ulcer. The possibility of multiple ulcers has also to be considered and in one of the non-aspirin cases at operation bleeding was found to be coming from a subacute gastric ulcer associated with a chronic duodenal ulcer, and in one aspirin case from an acute gastric ulcer with similar association. The proportion of patients bleeding from acute erosion after taking aspirin is, therefore, likely to be much higher than shown in Table I. This table also emphasizes the way in which aspirin ingestion appears to level up the incidence of ulceration as between the sexes, for the proportion of acute bleeding ulcers is actually much higher in women (67, with 48 aspirin takers out of 87 ulcer cases of all types) than in men (105, with 74 aspirin takers out of 227 ulcer cases). Men show the expected predominance in the chronic ulcers,
122 as against 20 , with great predominance in duodenal ulcers, 97 (exclusive of one found not bleeding) as against 13 in women (Table I).

The figure of $65 \%$ for recent aspirin ingestion in my cases is higher than the $40 \%$ described by Alvarez and Summerskill (1958) and the one in eight after ingestion of aspirin for all ulcers cases (one in five for acute ulcers) mentioned by Muir and Cossar (1955). It does, however, accord with the figure of $70 \%$ given by Stubbe (1958) as the proportion of his patients losing blood after aspirin ingestion. The possible cause for the high proportion of gastric casualties after taking aspirin seen by the writer as well as the symptoms for which aspirin was taken in the various cases will be discussed later.

The gastritis caused by aspirin is largely a direct traumatic irritation of the surface of the stomach by the aspirin and was first described by Douthwaite (1938), by Hurst and Lintott (1939), and subsequently very ably by Muir and Cossar (1955 and 1959). In a widely haemorrhagic and oedematous gastric mucosa, particularly on the lesser curve, one or more small erosions are seen, and the duodenal mucosa may be similarly affected. Aspirin appears to act as an irritant most easily on an empty stomach (Lange, 1957; Muir and Cossar, 1959), and, by provoking a marked hyperacidity in stomachs where the mucous secretion is also subnormal, as in cases of chronic duodenal ulcer. It is apparently less irritant in enteric-coated capsules (Lange, 1957; Scott, Porter, Lewis, and Dixon, 1961) but apart from Schneider's findings (1957) it has not been 
generally found that soluble aspirin ('calcium aspirin') is less irritant than acid acetylsal, which is converted into that time-honoured substance for removing corns from the feet (acid salicyl) when acted on by hydrochloric acid in the stomach. This epidermolytic effect (Ivy, Grossman, and Bachrach, 1950) may at times be enhanced by the ability of salicylates to cause gastric ulceration and haemorrhage after subcutaneous or intravenous injection (Dodd, Minot, and Arena, 1937; Grossman et al., 1961) so a high blood salicylate level may augment the local irritative effect. The bleeding seen in 110 of my cases after small, often very small, doses of aspirin would, however, seem to emphasize the importance of its local gastric effect. I did not observe general signs of aspirin sensitivity in any of my cases (Honigsberger, 1943).

To examine the relative irritative effects of various aspirin preparations on the market the patients were asked carefully not only about the dosage but also the type of aspirin preparation taken. The comparative results are seen in Table IV. At this point it is perhaps not out of place to comment on the diversity of names for aspirin preparations, a reflection of the general multiplicity of titles for pharmaceutical products with which the whole problem of therapy is hagridden at the present day. Some of the names imply an aspirin content but this is not so with others, and patients have volunteered to me that they knew that aspirin did not suit them but did not realize that such tablets as Alka-Seltzer, Phensic, Antoin, Veganin, Hypon, or even compound codeine tablets contained it. In the past, as has been pointed out (Jennings, 1963), some aspirin-containing products, notably Alka-Seltzer, have been widely and intensively advertised as being of benefit for digestive complaints. As can be seen from Table II the soluble 'calcium aspirins' (Disprin, etc.) are as liable as the less soluble 'acid' aspirin products to promote haemorrhage. The two less widely advertised preparations, Macprin and Paynocil, which contain glycine (aminoacetic acid) to make them disintegrate and freely dispersible, appear but little in the list; indeed Paynocil was only taken by one bleeding patient (a cirrhotic) and in company with other aspirin preparations. No cases of bleeding from sodium salicylate administration were observed (cf. also Baragar and Duthie, 1960) but Scott and his co-workers (1961) found it liable to cause gastric bleeding when in tablet form, but did not test ordinary strengths of mist. sod. sal. (cf. also Grossman et al., 1961).

In my series aspirin was taken as whole tablets, crushed tablets, and in suspension. As can be seen, many patients (110) bled after only a few tablets, i.e., less than four (cf. also Stubbé, 1958), and in the remaining 95 , some of whom took a mixture of a few tablets of one preparation with a few of another (e.g., aspirin and Phensic or Anadin and Hypon), there were those who, while taking aspirin regularly, only took two or three tablets in the day for pain or at night for sleep. The impression was strong that the tablets were most deleterious if taken on an empty stomach and particularly if so taken with some whisky or brandy in the time-honoured treatment for 'influenza'. In one case Disprin was taken with cortisone for rheumatism and this case is excluded. The other possible factors in promoting bleeding were often responsible for the symptoms for which the aspirin was taken (Tables III and VI),

TABLE II

NOS. OF CASES RELATED TO EACH TYPE OF ASPIRIN PREPARATION IN GASTRIC HAEMORRHAGE

\begin{tabular}{|c|c|c|c|c|}
\hline No. & ts Taken & & & Totals \\
\hline Acut & & Chro & & \\
\hline Few & Many & Few & Many & \\
\hline 28 & 31 & 10 & 14 & 83 \\
\hline 8 & 3 & 3 & 4 & 18 \\
\hline 9 & 1 & 10 & 8 & 28 \\
\hline 5 & 3 & 3 & 5 & 16 \\
\hline 2 & 2 & 1 & 1 & 6 \\
\hline 4 & 10 & 3 & 3 & 20 \\
\hline- & 2 & 1 & 1 & 4 \\
\hline- & - & - & 2 & 2 \\
\hline 1 & 1 & 2 & 1 & 5 \\
\hline 2 & - & - & - & 2 \\
\hline 11 & 13 & 5 & 7 & 36 \\
\hline- & 1 & - & & \\
\hline 2 & - & - & - & 2 \\
\hline $\begin{array}{l}\text { (Only } \\
72\end{array}$ & $\begin{array}{r}\text { sed by a } \\
67\end{array}$ & $\begin{array}{l}\text { otic w } \\
38\end{array}$ & e other & prep \\
\hline
\end{tabular}

'Soluble' aspirin tablets

Dispersible aspirin tablets

Aspirin

Alka-Seltzer

Anadin

A.P.C.

Codeine compounds

Hypon

Phensic

Veganin

Beecham's powders

Disprin and Codis

Antoin

Macprin

Paynocil

Totals

Many $=$ more than four tablets $;$ few $=$ four tablets or less

Free acid $=$ aspirin compounded with calcium carbonate and citric acid

Dispersible $=$ aspirin with amino acid (glycine). 
and these form an interlocking and interrelated complex which is a commentary on 'the way we live now'. Physical stress, tiring journeys, rushed meals, over-smoking, financial and business worries, poor sleep, and an increasing number of elderly people all were encountered frequently in the list. The part played by these influences in promoting gastric haemorrhage will now be considered individually, remembering all the while that headaches, muscle pains, and gastric discomforts, i.e., symptoms for which aspirin is taken, are liable to be their resultant symptoms. For this reason the aspirin cases are listed separately from the others. The effects of other irritants, including alcohol and smoking, are considered but all the results probably show numbers less than the actual, for histories are inadequate in very ill patients and in those averse to admitting to nervous influences or overindulgence. The main results are summarized in Table III and, since nervous influences appear to be most frequent, they are considered first.

NERVOUS FACTORS Nervous factors operating in people predisposed by their personality will cause a peptic ulcer if together the degree of predisposition and the amount of imposed nervous strain sufficiently disturb the patient. Family stress, bereavement, and financial trouble were fairly frequent amongst my patients in imposing such strain, and as an instance may be quoted the gastric ulcer patient (not in the series) who had his first haematemesis in 1944 after his son had been killed and who did not bleed again till after the death of his wife many years later.

William Brinton (London, 1857) first stated that 'mental anxiety so frequently coincides with ulcer that we are fully entitled to regard it as a more or less immediate cause'. The type of personality of the ulcer patient varies but with Sullivan and McKell (1950) I have found that emotional conflicts resulting in anxiety, hostility, resentment, and insecurity often occurred amongst my patients. As a result (Minski and Desai, 1955) they were restless and showed unusual drive and attempts at achievement. A ward containing a number of convalescent, ambulant gastric patients seen at a distance may be remarkably reminiscent of a lion's cage! This state of mind, which often requires sedation, is that which Alexander (1934) has stated to be responsible for chronic excitement of the stomach and it has since been shown (Wolf and Wolff, 1942, 1943) in their fistula subject, Tom, that anxiety and hostility cause hypersecretion, hypermotility, and hyperaemia of the gastric mucosa. Mittelmann, Wolff, and Scharf (1942) further showed that these and kindred destructive emotional reactions could reactivate peptic ulcers and cause recrudescence of symptoms. Davies and Wilson (1937 and 1939), in a controlled series of cases, found that emotional stress briefly preceded perforation or haematemesis in $84 \%$ of their cases. Melton (1940) found that the outbreak of war caused an increase in haematemesis and perforation, and while heavier work and increased smoking participated in this increase the predominant factor was marked nervous strain (Table III).

In my patients, without deep probing, tension, anxiety, and frustration were evident frequent associations of haematemesis; fear was active in a gas-holder attendant nervous of heights. It was often hard not to feel that the increased speed of modern life greatly accentuated these mental states, an impression which does not decrease with observations beyond the hospital walls.

In all there were 139 cases, 96 men and 43 women, showing definite evidence of nervous strain, and

TABLE III

OTHER INFLUENCES THAN ASPIRIN IN GASTRIC HAEMORRHAGE

\begin{tabular}{|c|c|c|c|c|c|c|c|c|}
\hline & & \multicolumn{2}{|c|}{ Aspirin Cases (205) } & \multicolumn{2}{|c|}{$\begin{array}{l}\text { Non-aspirin Cases } \\
(109)\end{array}$} & \multicolumn{2}{|l|}{ Totals } & \multirow[t]{2}{*}{ Grand Totals } \\
\hline & & $\begin{array}{l}\text { Acute } \\
\text { Ulcers }\end{array}$ & $\begin{array}{l}\text { Chronic } \\
\text { Ulcers }\end{array}$ & $\begin{array}{l}\text { Acute } \\
\text { Ulcers }\end{array}$ & $\begin{array}{l}\text { Chronic } \\
\text { Ulcers }\end{array}$ & Aspirin & Non-aspirin & \\
\hline \multirow[t]{2}{*}{ Nervous strain } & Male & 32 & 32 & 16 & 16 & 64 & $32(96)$ & \multirow{2}{*}{139} \\
\hline & Female & 22 & 2 & 13 & 6 & 24 & $19(43)$ & \\
\hline Physical strain & Male & 18 & 20 & 10 & 19 & 38 & $29(67)$ & 79 \\
\hline \multirow[t]{2}{*}{ Smoking } & Male & 29 & 40 & 12 & 30 & 69 & 42 (111) & \multirow{2}{*}{120} \\
\hline & Female & 2 & 5 & 1 & 0 & 8 & $1(9)$ & \\
\hline \multirow[t]{2}{*}{ Alcohol $^{1}$} & Male & $20(5)$ & $11(7)$ & $9(5)$ & $12(10)$ & 31 & $21(52)$ & \multirow[t]{2}{*}{57} \\
\hline & Female & 3 & 0 & $2(1)$ & 0 & 3 & $2(5)$ & \\
\hline \multirow[t]{2}{*}{ Acute infections (mainly respiratory) ${ }^{2}$} & Male & 17 & 15 & 2 & 2 & 32 & $4(36)$ & \multirow[t]{2}{*}{53} \\
\hline & Female & 13 & 2 & 2 & 0 & 15 & $2(17)$ & \\
\hline \multirow{3}{*}{$\begin{array}{l}\text { Chronic infections (mainly } \\
\text { respiratory) } \\
\text { Arteriosclerosis and hypertension }\end{array}$} & Male & 4 & 12 & 2 & 6 & 16 & $8(24)$ & \multirow[t]{2}{*}{28} \\
\hline & Female & 2 & 1 & 0 & 1 & 3 & $1(4)$ & \\
\hline & Male & 16 & 9 & 7 & 8 & 25 & $15(40)$ & 76 \\
\hline
\end{tabular}

${ }^{1}$ The figures in brackets show the approximate number of heavy drinkers in each group.

${ }^{2}$ Inclusive of chronic infection in exacerbation ( 11 cases). 
amongst these were 42 patients who were troubled by business worries, 33 from the aspirin list and nine from the non-aspirin list. There were also 48 patients whose worries were concerned with family affairs (illness, death, loss of home) and 19 of these were from the aspirin list and 29 from those in the non-aspirin list. It is interesting, but perhaps not surprising, to find that the main number of aspirin takers was in the business group, with 28 men out of 33 equally divided as cases of acute and chronic ulcer. In the non-aspirin group (nine) of business worriers all were men and seven had chronic ulcers. In the large group (29) of those with domestic worries, bleeding without aspirin, there was a slight predominance of women (15), with nine acute ulcers and six chronic as against eight acute and six chronic ulcers in men in this group. In the group of 19 with domestic worries who bled after aspirin, 13 were men and six were women, and, not surprisingly, there were eight acute ulcers in men and five acute ulcers in women amongst these, for many domestic crises are acute matters.

In the 49 cases not classified in these groups the emotional states of anxiety, tension, or agression were evident, but the history of precipitating trouble, if present, was not forthcoming; suppressed worry is of course particularly injurious to health (Avery Jones, 1957).

PHYSICAL STRAIN Seventy-nine patients were found in whom physical strain seemed to be the chief factor, or at least the presenting factor in precipitating haemorrhage. It is as difficult to separate the physical strain from the nervous tension which lies behind it as to classify the exact nature of a nervous strain where business and domestic issues have much interplay, as in two men who lost their jobs. Indeed four men with different types of ulcer suffered from the double strain of supporting seriously invalid wives (strokes, Cushing's syndrome) and carrying on with their work. Amongst the 79 patients rushed and often irregular meals were the most frequent finding and no doubt occurred more often than in the 49 who especially mentioned it; 27 of these came from the aspirin group and 24 of them were men. Thirteen of these patients had acute ulcers, and 11 were chronic, 10 being duodenal and one a stomal ulcer. Of the three women in the aspirin group one had a chronic duodenal ulcer and two had acute ulcers. In the non-aspirin group of 22 'meal-scampers' all were men apart from one woman with a chronic duodenal ulcer. In the male group there were 13 chronic ulcers, 11 duodenal and two gastric ulcers; eight in this group had acute ulcers.

The almost equal division of the total of 49 who scamped their meals between acute and chronic ulcers appeared to be related to the fact that in many of the patients with acute ulcers the meal routine had been more recently upset by increased work; in the patients with chronic ulcers as a general rule the bad habit was longstanding and often associated with heavy smoking. The greater proportion of acute ulcers in the aspirin group is not surprising. Only rarely did heavy work alone, or strain due to heavy lifting, seem to precede the bleeding.

Dental sepsis was only noteworthy in eight patients, and one of these, a chronic alcoholic with a chronic gastric ulcer, had an alveolar abscess. Two other patients had had teeth extracted just before admission but without much loss of blood till they took aspirin for jaw pain. Eight of the 10 patients had taken aspirin and seven of them had chronic ulcers; only two were women.

One young woman bled from an acute erosion just after giving a pint of blood to the blood bank. Two other patients had operations before bleeding, one a thumb amputation and the other his third unsuccessful hernia operation; both had acute ulcers but both had taken aspirin. One patient with a fractured femur had a haematemesis associated with aspirin a week after his accident, but I saw none of the spontaneous, gross erosive mucosal lesions so graphically described by Breckenridge, Walton, and Walker (1959). It is impossible to leave physical factors without mentioning the burden of age (to be considered later); of illness (such as in three cases of hemiplegia); pain as in arthritis, of which there were many cases, including five of painful spinal arthritis; or of the loss of a leg (one case). Of these, the three with most severe spinal arthritis, the one with a leg amputation, and two hemiplegics had chronic ulcers.

LOCAL IRRITATIVE FACTORS This group comprises heavy smokers and those who directly insulted the gastric mucosa by swallowing irritative substances, notably alcohol, and is additional to the aspirin group already described. As can be seen from Table III the majority of patients in this group had also taken aspirin.

Smoking Avery Jones (1957) has suggested that the increase in smoking may be directly related to the increased incidence of peptic ulcer. On the other hand Højer-Pedersen (1958) follows the 'oral dependence' theory of Alexander (1934) in considering that the conflicts in the ulcer personality predetermine a tendency to smoke and drink too heavily.

In my list, oversmoking, with 120 patients admitted for gastric haemorrhage, closely rivals 
nervous factors in the same complaint. Seventyseven of these patients had also taken aspirin recently and 43 had not. The predominance of men and of chronic ulcers in the two groups is evident from Table III, and of the 18 cases of men developing duodenal ulcer before the age of 40 years, 14 were heavy smokers and three of the others were alcoholics. Since the smoker may tend to underestimate his tobacco consumption, all those who confessed to 15 cigarettes daily or their equivalent in tobacco were placed in this group. As noted earlier many of them also had rushed and irregular meals. It should also be emphasized here that out of 37 men with business worries, 29 were heavy smokers, and 18 of these had chronic ulcers, usually duodenal, 11 patients coming from the aspirin group and seven from the non-aspirin bleeders. Two worried business women, who smoked very heavily, had ulcers, one acute, the other, less than 40 years of age, had a persistent duodenal ulcer.

Alcohol In my experience drinking alcohol may help to predispose to ulceration or may rapidly precipitate gastric bleeding. Those who bled after alcohol were grouped as: (1) 'heavy' drinkers, i.e., consistently heavy drinkers and those liable to very heavy bouts of drinking; and (2) 'provocative' drinkers, i.e., those who drank just beyond moderation, particularly at week-ends, or who took too stiff a 'curative' tot of spirits.

Of the group of heavy drinkers, there lay confessed $28 ; 12$ had also taken aspirin before bleeding and 16 had not. (Cases of hepatic cirrhosis are not grouped with these cases.) All were men except one woman who developed an acute ulcer as a result of recently drowning her domestic trouble in drink. Eighteen of the men had chronic ulcers (11 duodenal, eight gastric, and one with both ulcers). The prominence of gastric ulcer in this group is attributable to the fact that this type of ulcer follows chronic gastritis.

There were 29 cases of less heavy or 'therapeutic' drinking; 22 of these were associated with taking aspirin. Of the non-aspirin group, one patient was a young man who took 17 pints of beer to steady himself for the arrival of his first child, and another was a young provincial forgetting his business worries at a London party who was admitted drunk and vomiting blood; both had acute ulcers. Only four of the 29 were women, all with acute ulcers, and of the 25 men 19 had acute ulcers. As with smoking and worry, it would appear that the longer and harder the noxious influence is applied the more it is likely to cause chronicity in an ulcer.

Although my heaviest smoker (50 cigarettes daily) was also a heavy drinker, it is probable that not all the heavy drinkers were as ready to admit their smoking habits-or vice versa; but in all the alcohol takers there were 20 who admitted to heavy smoking and of these 11 also had business or domestic worry, eight coming from the aspirin group. A very small glass of wine taken at the end of a fast provoked bleeding in a Hebrew patient with a chronic duodenal ulcer.

Other irritants These include all other preparations which might have assisted gastric haemorrhage, either alone or in conjunction with other factors. None of the patients complained of recent ingestion of irritative solid food.

Phenylbutazone was taken just before haemorrhage in three ulcer cases seen in this series, and in one seen shortly afterwards. In one it was taken in conjunction with aspirin, in two alone, and in one with spirits. In all but the case outside the series, with severe spinal arthritis, the ulcers were acute. The action of phenylbutazone on the stomach is considered to be both local and systemic by Kirsner and Ford (1955), who found that it increased gastric acid flow, particularly in duodenal subjects.

Magnesium sulphate, as laxative 'salts' was taken, for 'rheumatism' in five cases: twice with aspirin, once with gin, once with tetracycline, and once alone. All these patients had acute ulcers except the last named and he had a large chronic gastric ulcer which required operation.

Only two patients had had anticoagulants (Dindevan): one with acute ulcer had been given Dindevan for femoral embolism from a severe mitral stenosis, and one with a large gastric ulcer causing chest pain was wrongly suspected of coronary thrombosis; he required operation.

Two patients received cortisone before bleeding; one with a short course also had aspirin, and quickly recovered from an acute erosion; the other after long treatment for rheumatoid arthritis died of a chronic gastric ulcer and a ruptured necrotic jejunum. In two further non-aspirin cases bleeding from acute erosions was preceded in one by sulphonamide therapy for tonsillitis and in the other by the use of an antihistamine preparation for giant urticaria.

INFECTIVE FACTORS My cases of infection (most were of respiratory type) were grouped into (a) acute or acute exacerbations of chronic and (b) chronic infection. Of the 70 cases in this group, 42 were acute, 11 were acute exacerbations of chronic infection, and 17 were of chronic infection only (Table III). A dental abscess and a neck carbuncle were included amongst the acute infections but all the others were respiratory and largely of the influenzal or severe coryzal type. Of the 53 patients in group (a), 39 bleedings were preceded by this type of infection and of these four developed pneumonia. In the chronic group of infections were 
tw'o men with extensive dental sepsis and chronic duodenal ulcers and one of these developed suppurative pneumonia after his haematemesis. $\mathrm{He}$ responded well to antibiotics, which were used in these cases whenever infected sputum or appreciable fever occurred. Otherwise the chronic infections were entirely chronic bronchitis with three cases of bronchiectasis. From Table III the predominence of aspirin-takers in this group (55 of the total) is apparent and supports Kelly's (1956) suggestion that taking aspirin for influenza is a frequent cause of gastric bleeding; 36 patients with acute ulcers in the aspirin-infection group is in accord with the expected effects of aspirin. Of these 36 , the majority had acute infections for which several, presumably feeling that fever, like sorrow, may yield to alcohol, had also taken a stiff dose of spirits.

It has long been recognized that virus infections may cause gastritis or may exacerbate pre-existing peptic ulcer symptoms (Emery and Monroe, 1935). Also that in chronic respiratory disease the additional elements of hypoxaemia and a tendency to visceral congestion from right heart decompensation both have adverse effects on the gastric mucosa (Avery Jones, 1957; Allibone and Flint, 1958; Flint and Warrack, 1958).

The association of chronic gastric and duodenal ulcers with chronic bronchitis and emphysema has been often remarked (Weber and Gregg, 1955; Latts, Cummins, and Zieve, 1956; Avery Jones, 1957). The proportion of chronic ulcers seen amongst my chronic infection cases is emphasized in Table III though, exceptionally, one of the three bronchiectatics died of right heart failure and a widespread haemorrhagic gastritis and duodenitis, probably because he had recently taken aspirin. Terminal haemorrhage from acute ulcers did however feature prominently in the cases of emphysema and chronic cor pulmonale of Flint and Warrack (1958), often in association with recent respiratory infection.

ARTERIOSCLEROSIS AND HYPERTENSION Most of the patients in this group were over 65 years of age but only those with marked vascular change were included, so the figures (Table III) are probably an understatement. One man of 39 years with very high blood pressure had an acute erosion after taking aspirin for headache, and of the other 75 patients 53 had taken aspirin for the aches and pains of old age. As has been mentioned, physical disability and the need to fend for oneself were prominent features of this group; the increased proportion of women in it (nearly one half) is noteworthy but not surprising.

Baker (1947) found hypertension in $5 \%$ of a series of 542 cases of bleeding ulcers mostly associated with mucosal lesions, in which he felt that the hypertension facilitated bleeding. Both Goldman (1936) and Kruse (1937) thought that arteriosclerosis was an important factor in causing heavy haemorrhage from peptic ulcers and in increasing the mortality rate.

OTHER CARDIOVASCULAR CONSIDERATIONS In one group of this series chronic cor pulmonale has been mentioned and in another fibrotic myocardial change resulting from coronary arteriosclerosis has been implied. Apart from these two groups little heart disease was encountered during the observations. There was one patient with an appreciable ventricular septal defect and a chronic ulcer; four were cases of chronic rheumatic heart, all with marked mitral disease and one with aortic reflux, and all with acute ulcers. There were also four cases of coronary thrombosis. One of these was terminal in an old man after a very heavy haemorrhage; the other three occurred respectively two years before, one year before, and one year after the gastric haemorrhage.

This dissociation between peptic ulcer and coronary thrombosis is also striking in the very large numbers of coronary thrombotic patients admitted to my wards; very few indeed have a gastric history to preclude the use of anticoagulants. Since stress is blamed for both disorders it is curious to find that it strikes above the belt in one group and below it in the other, but rarely in both places. Leaving aside all psychological consideration of repressed oral desires causing overstimulation of the gastrointestinal tract (Rosenbaum, 1954) I have been impressed with the marked physical overactivity and lack of obesity in my peptic ulcer patients and these two facts surely lessen the tendency to coronary thrombosis.

Other observers have found a varied linkage between peptic ulcer and coronary thrombosis. Walsh, Bland, Taquini, and White (1941) in 2,737 necropsies found no significant association between peptic ulcer and coronary disease. Morrison and Gonzalez (1952) felt that nervous (vagal) causes might lead to the two conditions in the same patient but also felt that the high lipoid content of many gastric diets might predispose to coronary disease, a possibility which was also stressed by Briggs, Rubenberg, O'Neal, Thomas, and Hartroft (1960). The liability of coronary thrombosis to occur in the elderly after severe ulcer haemorrhage, observed in my series, has also been noted by Crenshaw (1962).

OCCUPATIONAL FACTORS In their survey of the influence of occupation in the aetiology of peptic 
ulcer, Doll, Avery Jones, and Buckatzsch (1951) list the view of other investigators in this field, and the results are varied, probably to some extent as a result of the diversity of districts under review, though this does not entirely explain why doctors in Britain, found by Alsted (1942) and Doll et al. (1951) to have a high incidence of peptic ulcer, in Sweden (Ihre and Muller, 1943) showed a low incidence. Doll et al. (1951) also found responsible work (foremen and business executives) to bring a high incidence of ulcer and agricultural work to cause a low incidence (cf. also Alsted (1942)) ). The nature and position of my work brought no doctors or agricultural workers into the series, but many professional, responsible and skilled workers, and the high incidence of chronic duodenal ulcer in these, often heavy-smoking men, can be seen from Table IV, 38 such sufferers still being fully active whilst a number of the 24 retired had in their time been similarly employed. Doll et al. (1951) also did not find evidence of bus drivers being predisposed by their work to ulcer and there was only one such, with an acute ulcer, in my series. Five patients in all, who did not take aspirin, drove large vehicles and three of these had acute ulcers. In the aspirin cases the train driver had an acute ulcer and the two long-distance lorry drivers had chronic duodenal ulcers. One of these improved with new work, but the figures are not impressive, hardly a surprising fact when a large proportion of my patients were car drivers, often under trying conditions.

With Doll et al. (1951) I did not find shift work markedly detrimental to the stomach, only two of my patients blaming this mode of working.

INTRINSIC FACTORS If we exclude the personality of the patients the main intrinsic factors to be considered are those of sex, age, family history, and blood group.

Sex There is a great preponderance of men amongst cases of chronic ulcers $(122: 20)$ with a particular male predisposition in duodenal ulcers
(97 : 13) and a smaller predisposition in chronic gastric ulcers $(25: 7)$. Two male stomal ulcers, classified as gastric, occurred in former sufferers from duodenal ulcer. Hanley (1964) correlates this male prevalence in ulcer formation with the greater secretory mass of peptic cells found in men.

In acute ulcers there is, in my series, a great levelling up between the sexes (105 men to 67 women), and particularly in the aspirin group ( 74 men to 48 women). In these cases the effect of local gastric trauma is paramount and other considerations of less import, but it is noteworthy that women subject to major strains in the competitive world of business and industry tend to develop chronic ulcers, and the factor of sex, as compared with the environmental effects, dwindles in importance.

Age Up to a point it may be said that the older we get the greater are our chances of peptic ulcer. Cates (1959) found that in men gastric bleeding showed an appreciable increase in the fourth decade; was high in the fifth, sixth, and seventh decades, and fell off in the eighth decade; in women the increase was gradual from the fourth to the eighth decade. As can be seen from Table I my figures concur with these findings in all classes of ulcer except in the female chronic list which is too small to be significant. The age of decrease in the incidence of ulcer or haematemesis coincides with the age of decreasing numbers at risk.

Family history A clear family history of one or more near relations with peptic ulcer was found in 34 cases, 24 from the aspirin list and 10 others. Of these, 21 (13 men and eight women) had acute ulcers though one man had previously had a duodenal ulcer. Apart from this man there were 13 chronic cases (11 men and two women) and one of these, a man of 21 years, with a chronic duodenal ulcer, had three close relatives affected. Whether on the total reckoning or on that of chronic ulcers alone, $10 \%$ had a positive family history. The precise significance of this figure has to be viewed with

TABLE IV

OCCUPATIONAL CATEGORIES OF ULCER PATIENTS

\begin{tabular}{|c|c|c|c|c|c|}
\hline \multicolumn{3}{|c|}{$\begin{array}{l}\text { Professional, Responsible, } \\
\text { Skilled, Self-employed }\end{array}$} & \multicolumn{3}{|c|}{$\begin{array}{l}\text { Semi-skilled and } \\
\text { Subordinate Posts }\end{array}$} \\
\hline Acute & $\begin{array}{l}\text { Chronic } \\
\text { Duo- } \\
\text { denal } \\
\text { Ulcer }\end{array}$ & $\begin{array}{l}\text { Chronic } \\
\text { Gastric } \\
\text { Ulcer }\end{array}$ & Acute & $\begin{array}{l}\text { Chronic } \\
\text { Duo- } \\
\text { denal } \\
\text { Ulcer }\end{array}$ & $\begin{array}{l}\text { Chrcnic } \\
\text { Gastric } \\
\text { Ulcer }\end{array}$ \\
\hline 35 & 22 & 1 & 13 & 12 & 5 \\
\hline 2 & - & - & 2 & 1 & - \\
\hline 6 & 16 & 2 & 13 & 7 & 4 \\
\hline- & - & - & 2 & 1 & - \\
\hline 43 & 38 & 3 & 30 & 21 & 9 \\
\hline
\end{tabular}

\begin{tabular}{|c|c|c|c|c|c|}
\hline \multicolumn{3}{|c|}{ Unskilled } & \multicolumn{3}{|c|}{ Household Duties ${ }^{1}$} \\
\hline Acute & $\begin{array}{l}\text { Chronic } \\
\text { Duo- } \\
\text { denal } \\
\text { Ulcer }\end{array}$ & $\begin{array}{l}\text { Chronic } \\
\text { Gastric } \\
\text { Ulcer }\end{array}$ & Acute & $\begin{array}{l}\text { Chronic } \\
\text { Duo- } \\
\text { denal } \\
\text { Ulcer }\end{array}$ & $\begin{array}{l}\text { Chronic } \\
\text { Gastric } \\
\text { Ulcer }\end{array}$ \\
\hline
\end{tabular}

Retired

Acute Chronic Chronic

\begin{tabular}{|c|c|c|c|c|c|c|c|c|c|c|c|c|c|}
\hline Aspirin & Men (143) & 35 & 22 & 1 & 13 & 12 & 5 & 10 & 8 & 3 & - & - & - \\
\hline cases (205) & Women (62) & 2 & - & - & 2 & 1 & - & 9 & - & - & 23 & 6 & 3 \\
\hline Non-aspirin & Men (84) & 6 & 16 & 2 & 13 & 7 & 4 & 7 & 8 & 2 & - & - & - \\
\hline cases (109) & Women (25) & - & - & - & 2 & 1 & - & 2 & 2 & - & 10 & 2 & - \\
\hline & Totals & 43 & 38 & 3 & 30 & 21 & 9 & $2 \overline{8}$ & $1 \overline{8}$ & 5 & 33 & 8 & 3 \\
\hline
\end{tabular}

'Six housewives from aspirin group and two from non-aspirin group with other work are placed in semi-skilled and unskilled categories. 
environmental factors also in mind: the influence of nervous relations, family difficulties, heavy smokers in the family, and so on. One nervous woman with haematemesis confided that all her family were nervous and that her nephew developed his ulcer on D day. Many of those with a family history of ulcers were tense and anxious, and 13 were heavy smokers; the young man with the strongest family history was both. Further, since families often lean to the same occupation the family tendency to ulcer may, in part, at least, be determined by the environment at work. The family job and the family habits as well as the family personality may well be expected to predispose to family ulcers.

Although my figures, from which seven cases (four chronic and three acute) have been excluded because of incomplete evidence, do not greatly support the strength of inheritance of the ulcer tendency, Doll and Kellock (1951) did find that their two groups of cases of duodenal and gastric ulcer each had an independent hereditary factor. Despite this, Cleave (1962) is convinced that environmental factors are of far greater importance, a view supported by the persistently rising ulcer rate.

BLOOD GROUPS The hereditary factor in chronic peptic ulcer noted by Doll and Kellock (1951) can now be related to the observations of Roberts (1957) that duodenal ulcer is associated particularly with blood group $\mathbf{O}$ and that so to a lesser extent is gastric ulcer. Another feature of some hereditary significance is the associated finding of salivary $\mathrm{ABO}$ nonsecretion in duodenal ulcer (Clarke, Edwards, Haddock, Howel-Evans, McConnell, and Sheppard, 1956). In gastric ulcer patients Buckwalter and Van Scoy (1961) have found an increased frequency of blood group $O$ in gastric ulcer patients and to a lesser extent in their siblings. In gastric carcinoma they follow other writers (Roberts, 1957; Race and Sanger, 1958) in relating the disease to blood group $A$ and to a lesser extent they found the same group in the siblings of these patients.

In 40 of my cases, taken at random, there were 21 from group $\mathrm{O}, 14$ from group $\mathrm{A}$, three from group $\mathrm{B}$, and two from group $\mathrm{AB}$. No significant results can be deduced from such small numbers but seven of the patients with chronic duodenal ulcers were in group $\mathrm{O}$, two in group $\mathrm{A}$, and one in group $\mathrm{B}$. The group $O$ cases included no chronic gastric ulcer but the one case of gastric carcinoma tested was in group A.

SEASONAL INFLUENCE Avery Jones (1957) found most admissions for bleeding from ulcers in the months of December, January, and February and least in June and July. Kelly (1956) found an increase of bleeding in the spring and autumn which he felt might be ascribed to the aspirin treatment of virus infections during those seasons. My figures (Table V) show the expected drop in June and July, but surprisingly high figures for August. There was no clear reason for this last, but it may te related to attempts to cover holiday absentees or even to the added stresses which affluence and the motor car now introduce into the holiday season.

The expected high figures in the first three months of the year certainly bear relationship to the virus infections prevalent at that time of year and to their popular treatment with aspirin. Also the greater strain of work at that time of year appeared to influence some cases.

OTHER CONDITIONS CAUSING BLEEDING During the four years there were 24 admissions for bleeding in addition to the 314 admissions for bleeding from peptic ulcer. In the aspirin group there were 16 admissions: five patients with hiatus hernia; six with hepatic cirrhosis; three with gastric carcinoma; one women with a gastric leiomyoma; and one young man with haemophilia. There was only one man with hiatus hernia in this group and one woman with cirrhosis, but the cases of gastric carcinomata were all in men. One of these was successfully treated by operation as was one hiatus hernia and the leiomyoma.

The non-aspirin group of eight were all men. There were three cases of hiatus hernia, one having an acute peptic ulcer at the lower end of a short oesophagus. There were also three cases of gastric carcinoma and two of hepatic cirrhosis. One of the

TABLE V

SEASONAL INCIDENCE

\begin{tabular}{|c|c|c|c|c|c|c|c|c|c|c|c|c|}
\hline & \multicolumn{12}{|l|}{ Month } \\
\hline & January & February & March & April & May & June & July & August & September & October & November & December \\
\hline $\begin{array}{l}\text { Aspirin (acute ulcers) } \\
\text { Aspirin (chronic ulcers) } \\
\text { Total } \\
\text { Non-aspirin (acute) } \\
\text { Non-aspirin (chronic) } \\
\text { Total } \\
\text { Grand total }\end{array}$ & $\begin{array}{r}13(6) \\
7(2) \\
20(8) \\
4(2) \\
9(1) \\
13(3) \\
33(11)\end{array}$ & $\begin{array}{r}10(3) \\
11(3) \\
21(6) \\
7(3) \\
1(0) \\
8(3) \\
29(9)\end{array}$ & $\begin{array}{r}8(1) \\
9(2) \\
17(3) \\
4(1) \\
7(1) \\
11(2) \\
28(5)\end{array}$ & $\begin{array}{r}6(4) \\
8(1) \\
14(5) \\
2(1) \\
2(0) \\
4(1) \\
18(6)\end{array}$ & $\begin{array}{r}8(2) \\
5(0) \\
13(2) \\
8(4) \\
5(1) \\
13(5) \\
26(7)\end{array}$ & $\begin{array}{r}4(1) \\
3(1) \\
7(2) \\
3(0) \\
4(0) \\
7(0) \\
14(2)\end{array}$ & $\begin{array}{r}10(4) \\
4(0) \\
14(4) \\
4(2) \\
4(0) \\
8(2) \\
22(6)\end{array}$ & $\begin{array}{r}13(5) \\
8(1) \\
21(6) \\
5(3) \\
9(1) \\
14(4) \\
35(10)\end{array}$ & $\begin{array}{r}10(4) \\
4(2) \\
14(6) \\
2(0) \\
4(0) \\
6(0) \\
20(6)\end{array}$ & $\begin{array}{c}16(9) \\
7(1) \\
23(10) \\
7(3) \\
7(2) \\
14(5) \\
37(15)\end{array}$ & $\begin{array}{r}13(5) \\
10(0) \\
23(5) \\
3(0) \\
5(0) \\
8(0) \\
31(5)\end{array}$ & $\begin{array}{r}11(4) \\
7(1) \\
18(5) \\
1(0) \\
2(0) \\
3(0) \\
21(5)\end{array}$ \\
\hline
\end{tabular}

Total figures and (in brackets) no. of female cases 
patients with carcinoma had a successful operation; the other two died. It should be emphasized that all the patients with hiatus hernia may well have also had acute peptic ulcers for, as Davidson (1958) has remarked, the ulcers in these cases, often occurring at the anterior margin of the gastric narrowing, are difficult to see in radiographs. One of my cases of this type bled 10 days after taking a moderate dose of aspirin. This patient was not counted in with the ulcer cases, but all who had no more than a small gastric protrusion above the diaphragm were so reckoned.

\section{SYMPTOMS TREATED BY ASPIRIN}

The predominant symptoms for which aspirin was taken are shown in Table VI in which the inducements to aspirin are arranged in order of frequency. A few patients had two equal symptoms e.g., headache and arthritis, dyspepsia and insomnia, and a few took aspirin with little reason, but most had one chief symptom for relief. In the greatest number (66) this symptom was gastric discomfort: nervous dyspepsia, flatulence, or the more severe pains of chronic duodenal ulcer. One of this group, suffering from severe pain penetrating into his back, read in the daily press of the pain-killing properties of codeine and, not realizing that such tablets contained aspirin, bought a large bottle of them and for each pain went to the bottle and turned a number of tablets into his palm and swallowed them with a little water. The power of television and the press and the confusing nomenclature of aspirin-containing tablets must be blamed for the type of severe haemorrhage which ensued in this case and required operation. It is most unfortunate that aspirin has come to be taken so frequently for the very group of complaints where it is likely to be most hurtful. For such complaints as influenza (often together with the added menace of spirits), 'rheumatism', arthritis, and headache, aspirin is of course a time-honoured

\section{TABLE VI}

PRINCIPAL CAUSES LEADING TO TAKING ASPIRIN

\begin{tabular}{lc} 
Principal Cause & No. of Cases \\
\hline $\begin{array}{l}\text { Stomach pains (from both organic and functional } \\
\text { dyspepsia) }\end{array}$ & 66 \\
$\begin{array}{l}\text { Infections (mainly acute respiratory) } \\
\text { Headaches }\end{array}$ & 42 \\
Limb pains (osteoarthritic, muscular, sciatic, etc.) & 40 \\
Mental symptoms (worry, tension, etc.) & 26 \\
Insomnia (often in old age) & 18 \\
Backache (osteoarthritis etc.) & 13 \\
Toothache & 10 \\
Anorexia (or as tonic or prophylactic) & 8 \\
Colic & 3 \\
Post-operative (thumb) & 1 \\
& Total \\
\end{tabular}

remedy and is taken deliberately but without knowledge of its possible ill consequences. In many such cases it is naturally taken on an empty stomach when its ill effect is likely to be most serious.

\section{TREATMENT AND OUTCOME}

It is not the purpose of this paper to deal in detail with treatment. The patients described bled in amounts from a few ounces to heavy and recurrent bleeds associated with severe shock. Rest, with adequate blood transfusion and anti-shock measures where required, were the main elements of treatment. Where necessary, sedatives were used to secure rest and the patients were given increasing gastric diets after initial short periods on largely fluid or soft food; alkalis and anticholinergic drugs were given in the usual manner, as were iron and ascorbic acid. In dealing with such a large number of aspirinpreceded haemorrhages and, therefore, with many presumed acute lesions, I attempted wherever possible to avoid operative interference (c.f. Gilmour, 1961). The patients who had bled with moderate severity were, therefore, given an initial transfusion of 2 or, at the most, 3 pints of blood (1 to 1.5 litres) in the belief that overloading of the circulation with large volumes of blood was likely to restart a subsiding haemorrhage. In a case where the history strongly suggested acute erosion this type of transfusion was repeated, if renewed bleeding became evident, but a still further bleed was taken as an indication for surgery. Only seven such cases came to operation, one woman and six men from the aspirin group, and one of the men had a chronic duodenal ulcer as well as acute ulceration. These seven are evidence that it is not always possible by conservative measures to arrest the severe bleeding which may occur in acute erosive haemorrhagic gastritis. But they are a very small minority and it is notable that all followed ingestion of aspirin.

In those with a history suggestive of chronic ulceration, operation was done for the second appreciable bleeding and in this group were 25 cases, 16 after aspirin and nine not so treated. There were eight gastric ulcers (four in each group) and 17 duodenal ulcers, 12 after aspirin; 16 of the duodenal ulcers were in men. Of the chronic gastric ulcer group only one (in the aspirin list) was a woman, and one man in the other list had a subacute gastric ulcer associated with a chronic duodenal ulcer. Avery Jones has found the need for operation greater in old patients, and though the ages were widely distributed in my cases (Table I), nine of them were over 65 years.

All the seven acute ulcer cases needed emergency operation, as amongst chronic ulcers did $\mathbf{1 0}$ of the 
aspirin group and five of the non-aspirin group. In the others a slightly delayed operation was performed when the patients were in optimal condition; these cases had nearly all had earlier haemorrhages. Other cases of chronic ulcer on the lists were treated by still later operation, but are not considered here.

\section{COMMENT}

Three hundred and thirty-eight patients admitted for upper alimentary bleeding were seen in four years in one general medical unit, and these were only part of the hospital admissions for this cause. Even those who dispute the existence of an 'ulcer personality' could not, from my evidence, overlook a large group of tense, conscientious, self-driving and even aggressive people in such admissions. With modern conditions of business routine, and to a less extent of domestic life, as competitive as they are, these people pressing into the front of the battle are likely casualties. Misfortune, fear, fatigue, fuss, frustration, frenzy, and even folly and infection, are all hostile influences. Self-inflicted and environmental effects were a detrimental combination in many of my patients, leading to acute or chronic ulceration.

Pulvertaft (1959) has shown the effect of urbanization in leading to increase in ulcer incidence, and the consequences of urbanization, bad mental habits, e.g., anxiety, bad physical routine (fatigue, rushed meals, oversmoking), and bad medication lead on through gastric disorders and ulcers to gastric bleeding.

We have now passed from the 'aspirin age' into the 'tablet age' but still far too much aspirin is taken without due thought or as a result of unscrupulous advertisement. Why it causes bleeding in some and not in others has been implied by my findings. There is more than presumptive evidence that the group of people just considered were most likely to have gastric mucosal congestion (Wolf and Wolff, 1942, 1943; Mittelmann, Wolff, and Scharf, 1942) whether they had an ulcer or not, and unfortunately under present conditions this kind of group is most prone to take aspirin. Aspirin is thus one large factor amongst the many which add together to produce a haemorrhagic ulcer. If it causes bleeding before chronic ulceration has occurred then an improved régime may avert persistent trouble, but where the warning is not heeded chronic ulceration has been found to follow. It is suggested that the failure of ulcers to heal is due to strong and continued action on the gastric mucosa of such noxious influences as have been described. The action of aspirin is certainly local and irritative; it is also suggested that it may either have a lesser effect from

\section{TABLE VII}

CAUSES OF DEATH IN ALL CASES OF BLEEDING

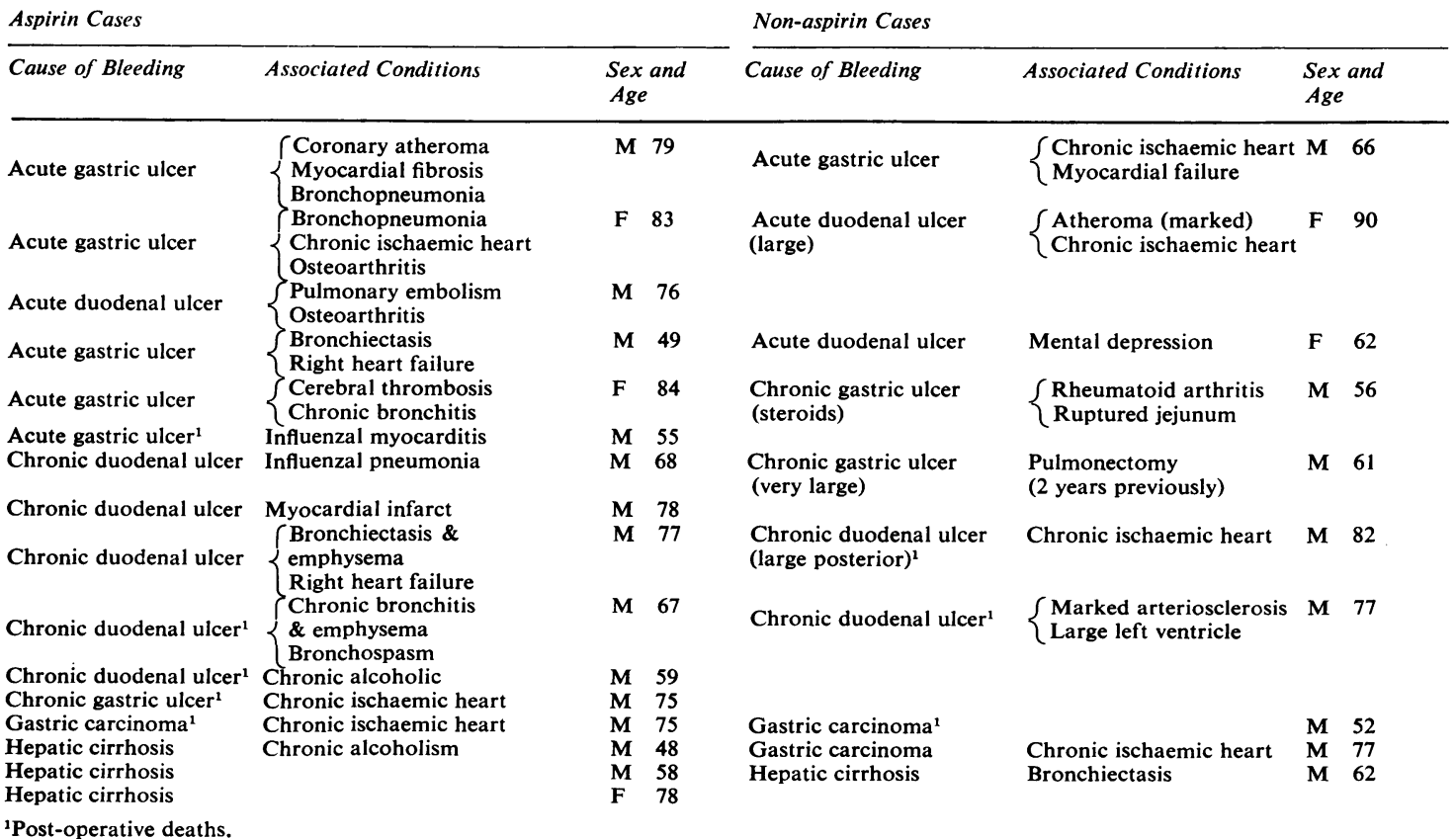


the hypothalamus via the vagi or through the gastric blood supply.

After aspirin, even acute ulcerations, which can be widespread, may necessitate surgical treatment but my findings suggest that the need for immediate surgical treatment of bleeding ulcers has been greatly diminished in recent years by the greater use of judicious blood transfusion (Kekwick, Maycock, Marriott, and Whitby, 1941).

Of the 24 assorted cases of bleeding (16 after aspirin) seven came to operation, including four patients with gastric carcinoma, one developing in a chronic simple gastric ulcer. The other three cases were of leiomyoma, hepatic cirrhosis, and hiatus hernia.

Of the admissions for ulcer, seven out of 172 patients with acute ulcers $(4 \%)$ and 25 out of 142 with chronic ulcers $(17.6 \%)$ came to operation immediately or soon after bleeding. Of these, three ulcers were also on the point of perforation, four were penetrating, and one duodenal ulcer was stenosed. There was an operative mortality of five $(15.6 \%)$, one in a case of acute ulcer and four in chronic ulcers. The patient with acute ulcer had toxic myocarditis from influenza; one of the patients with chronic ulcer who died was a chronic alcoholic; one had severe chronic bronchitis and asthma; the other two were respectively $\mathbf{7 5}$ and 82 years of age.

Cates (1959) has pointed out that haematemesis patients do not often die as a direct result of a bleeding ulcer but from associated conditions. This was as true of my non-operative deaths as of those just mentioned, as can be seen from Table VII. There were in all 14 ulcer deaths in this group out of 314 admissions (less than $4.5 \%$ ).

Some patients were temperamentally or socially unable to control their ulcers by dietary care and moderation in alcohol and tobacco; they later required operation. The others who did not come to operation have been followed in large numbers and as a result of improved régimes most have maintained satisfactory health, though a few have needed operation. Those who have kept well have benefited from the dramatic warning given by the bleeding to mend their ways, a result not unlike the result of the heeded warning of a haemoptysis in pulmonary tuberculosis.

In my lists were three patients who had had a previous gastroenterostomy and eight with partial gastrectomy. Two of the gastroenterostomy cases had stomal ulcers, but all the other cases had acute lesions, though one chronic alcoholic who had had partial gastrectomy for duodenal ulcer later developd a chronic gastric ulcer. Two other cases, a man and a woman, first seen with acute ulcers, developed gastric craters after prolonged domestic trouble, the woman, after bereavement, showing both gastric and duodenal ulcers.

In general I have found gastric ulcers more responsive to medical treatment than are duodenal ulcers.

\section{SUMMARY}

The cause for bleeding from the upper alimentary tract has been considered in 321 cases from a suburban area in 338 consecutive admissions for this symptom. The expected predominance of men was found amongst the admissions for ulcer, 227 men and 87 women, but the number of patients bleeding from acute gastric erosion after aspirin (205) has increased the proportion of women in the series. It is suggested that aspirin causes an acute erosive gastritis mainly by local action and that this may also be the cause of bleeding even when a chronic ulcer is present. For this reason an attempt was made to defer operation in all patients bleeding after aspirin and in the series only 22 of the 314 patients with bleeding ulcers needed emergency operations. Only one patient, a woman of 62 suffering from marked mental depression, died merely as a result of heavy bleeding without having an operation. The other 18 patients who died due to ulcer, whether post-operative or otherwise, all had serious physical disability.

That aspirin causes bleeding in some and not in others appears to be due to the fact that some have an increased acid-pepsin secretion in their stomachs. The association of this state with family inheritance, the blood group, and the ABH salivary secretion is mentioned, but the series particularly seemed to emphasize the importance of extrinsic factors: excessive emotion, fatigue, anxiety, infection, alcohol, irregular meals, and heavy smoking. It is concluded that these factors, which can increase gastric acidity or cause gastritis, can also thereby facilitate the erosive effect of aspirin. 'The gun must be loaded in order for an explosion to occur when salicylates pull the trigger' (Grossman et al., 1961). And my cases also suggest that when a number of the malign influences just mentioned are conjoined then an intensification of one or more may precipitate the haemorrhagic explosion without the triggering influences of salicylates. They further suggest that these influences, becoming more frequent and intense in present-day urban life, are the causes of the observed increase in the number of peptic ulcers. This type of life does tend to lead to taking aspirin, so caution against its indiscriminate use and advertisement is enjoined.

In the series a divergence is also noted between 
the incidence of peptic ulcer and another increasingly common complaint often attributed to stress, coronary thrombosis.

That hereditary did not play a large causative part in the series may be attributed partly to the strength of operative extrinsic influences and partly to the large proportion of acute ulcers. In a one-man survey the results must necessarily be part impressionistic but I have tried to leave a large assembly of facts to speak for itself.

I am indebted to my colleague, Dr. Eric Topham for the very considerable help he has given me in the radiographic investigation of my cases.

\section{REFERENCES}

Alexander, F. (1934). The influence of psychological factors upon gastro-intestinal disturbances: a symposium. Psychoanal. Quart., 3, 501-539.

Allibone, A., and Flint, F. J. (1958). Bronchitis, aspirin, smoking and other factors in the aetiology of peptic ulcer. Lancet, 2, 179-182.

Alsted, G. (1942). Ulcussygdommens geografiske og ernhvervsmaessige, forekomst i Danmark. Ugeskr. Laeg., 104, 1430-1439.

Alvarez, A. S., and Summerskill, W. H. J. (1958). Gastrointestinal haemorrhage and salicylates. Lancet, 2, 920-925.

Baker, C. G. (1947). Bleeding peptic ulcer. Guy's Hosp. Rep., 96, 1-56.

Baragar, F. D., and Duthie, J. J. R. (1960). Importance of aspirin as a cause of anaemia and peptic ulcer in rheumatoid arthritis. Brit, med. J., 1, 1106-1108.

Breckenridge, I. M., Walton, E. W., and Walker, W. F. (1959). Stress ulcers in the stomach. Ibid., 2, 1362-1364.

Briggs, R. D., Rubenberg, M. L., O'Neal, R. M., Thomas, W. A., and Hartroft, W. S. (1960). Myocardial infarction in patients treated with Sippy and other high-milk diets. Circulation, 21, 538-542.

Brinton, W. (1857). On the Pathology, Symptoms and Treatment of Ulcer of the Stomach, pp. 95-96. Churchill, London.

Buckwalter, J. A., and Van Scoy, R. E. (1961). ABO blood groups of siblings of gastric ulcer and gastric carcinoma patients. Brit. med. J., 1, 1585-1587.

Cates, J. E. (1959). Review of 300 patients with haematemesis or melaena. Ibid., 1, 206-211.

Clarke, C. A., Edwards, J. W., Haddock, D. R. W., Howel-Evans, A. W., McConnell, R. B., and Sheppard, P. M. (1956). ABO blood groups and secretor character in duodenal ulcer. Ibid. $2,725-731$.

Cleave, T. L. (1962). Peptic Ulcer, pp. 110-112. Wright, Bristol.

Crenshaw, J. F. (1962). Complications of peptic ulcer following acute myocardial infarction. Clin. Med., 69, 2621-2630.

Davidson, J. S. (1958). Gastric ulcer in association with hiatus hernia. Lancet, 2, 729-731.

Davies, D. T., and Wilson, A. T. M. (1937). Observations on the life history of chronic peptic ulcer. Ibid., 2, 1353-1360.

- - (1939). Personal and clinical history in haematemesis and perforation. Ibid., 2, 723-727.

Dodd, K., Minot, A. S., and Arena, J. M. (1937). Salicylate poisoning and explanation of the more serious manifestations. Amer. J. Dis. Child., 53, 1431-1446.

Doll, R., Jones, F. Avery, and Buckatzsch, M. M. (1951). Occupational factors in the aetiology of gastric and duodenal ulcers. Spec. Rep. Ser. med. Res. Coun. London, No. 276.

- - , and Kellock, T. D. (1951). The separate inheritance of gastric and duodenal ulcer. Ann. Eugen. (Lond.), 16, 231-240.

Douthwaite, A. H. (1938). Some recent advances in medical diagnosis and treatment. Brit. med. J., 1, 1143-1146.

Emery, E. S., Jr., and Monroe, R. T. (1935). Peptic ulcer: nature and treatment based on a study of 1435 cases. Arch. intern. Med., $55,274-292$.

Flint, F. J., and Warrack, A. J. N. (1958). Acute peptic ulceration in emphysema. Lancet, 2, 178-179.

Gilmour, J. (1961). The surgical aspects of gastritis and its role in gastric pathology. Brit. J. Surg., 49, 278-288.
Goldman, L. (1936). Gross hemorrhage from peptic ulcer. J. Amer. med. Ass., 107, 1537-1542.

Grossman, M. I., Matsumoto, K. K., and Lichter, R. J. (1961). Faecal blood loss produced by oral and intravenous administration of various salicylates. Gastroenterology, 40, 383-388.

Hanley, W. B. (1964). Hereditary aspects of duodenal ulceration. Brit. med. J., 1, 936-940.

Højer-Pedersen, W. (1958). On the significance of psychic factors in development of peptic ulcer. Acta psychiat. scand., Suppl. 119, 27-135.

Honigsberger, M. (1943). Aspirin and gastric haemorrhage. Brit. med. J., $2,57$.

Hurst, Sir A., and Lintott, G. A. M. (1939). Subacute ulceration of the stomach with achlorhydria. Guy's Hosp. Rep., 89, 177-183.

Ihre, B. J. E., and Muller, R. (1943). Gastric and duodenal ulcer: study of 1193 cases. Acta med. scand., 116, 33-57.

Ivy, A. C., Grossman, M. I., and Bachrach, W. H. (1950). Peptic Ulcer, p. 262. Blakiston, Philadelphia.

Jennings, G. H. (1963). Alka-Seltzer and haematemesis. Brit. med. J., $1,475$.

Jones, F. Avery (1957). Clinical and social problems of peptic ulcer. Ibid., 1, 719-723, 786-793.

Kelly, J. J., Jr. (1956). Salicylate ingestion; a frequent cause of gastric hemorrhage. Amer. J. med. Sci., 232, 119-128.

Kekwick, A., Maycock, W. D'A., Marriott, H. L., and Whitby, L. E. H. (1941). Diagnosis and treatment of secondary shock. Lancet, 1, 99-104.

Kirsner, J. B., and Ford, H. (1955). Phenylbutazone (butazolidin)studies on the stimulaion of gastric secretion and the formation of peptic ulcer in man. Gastroenterology, 29, 1-17.

Kruse, F. H. (1937). The complications of peptic ulcer and their treatment. J. Amer. med. Ass., 109, 868-874.

Lange, H. F. (1957). Salicylates and gastric haemorrhage. Gastroenterology, 33, 770-788.

Latts, E. M., Cummins, J. F., and Zieve, L. (1956). Peptic ulcer and pulmonary emphysema. Arch. intern. med., 97, 576-584.

Melton, G. (1940). Haematemesis and the war. Lancet, 1, 316-317.

Minski, L., and Desai, M. M. (1955). Aspects of personality in peptic ulcer patients: a comparison with hysterics. Brit. J. med. Physcol., 28, 113-134.

Mittelmann, B., Wolff, H. G., and Scharf, M. P. (1942). Emotions and gastroduodenal function. Psychosom. Med., 4, 5-61.

Morrison, L. M., and Gonzalez, W. F. (1952). The relationship of chronic peptic ulcer to coronary thrombosis. Amer.J. med. Sci., 224, 314317.

Muir, A., and Cossar, I. A. (1955). Aspirin and ulcer. Brit. med. J., 2, 7-12.

539-541.

Pulvertaft, C. N. (1959). The incidence of peptic ulcer in town and country. Proc. World Cong. Gastroent., Baltimore 1958, 1, 364-367.

Race, R. R., and Sanger, R. (1958). Blood groups in man, pp. 320-323. Blackwell, Oxford.

Roberts, J. A. F. (1957). Blood groups and susceptibility to disease: a review. Brit. J. prev. soc. Med., 11, 107-125.

Rosenbaum, M. (1954). Recent Development of Psychosomatic Medicine, edited by E. D. Wiltkower and A. A. Leghorn. Lippincott, Philadelphia.

Schneider, E. M. (1957). Aspirin as a gastric irritant. Gastroenterology, $33,616-620$

Scott, J. T., Porter, I. H., Lewis, S. M., and Dixon, A. St. J. (1961). Studies of gastrointestinal bleeding caused by corticosteroids, salicylates and other analgesics. Quart. med. Review, 30, 167-188.

Stubbé, L. Th. F. L. (1958). Occult blood in faeces after administration of aspirin. Brit. med. J., 2, 1062-1066.

Sullivan, A. J., and McKell, T. E. (1950). Personality in Peptic Ulcer, Thomas, Springfield, Illinois.

Walsh, B. J., Bland, E. F., Taquini, A. C., and White, P. D. (1941). The association of gall bladder disease and of peptic ulcer with coronary disease; a post-mortem study. Amer. Heart J., 21, $689-698$.

Weber, J. M., and Gregg, L. A. (1955). The coincidence of benign gastric ulcer and chronic pulmonary disease. Ann. int. Med., 42, 1026-1030.

Wolf, S., and Wolff, H. G. (1942). Evidence on the genesis of peptic ulcer in man. J. Amer. med. Ass., 120, 670-674. (1943). Human Gastric Function, pp. 118-120. Oxford University Press, New York. 